

Secretario Técnico

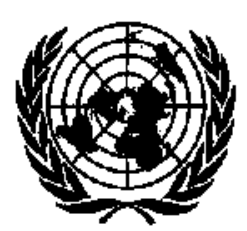

NACIONES UNIOAS 
Tres formas de coordinación social

Norbert Lechner

Brechas sociales en Colombia

Juan Luis Londoño de la Cuesta

Los Estados Unidos al rescate: la asistencia flnanciera a México en 1982 y 1995

Nora Lustig

El réglmen de convertibllidad y el sistema bancario en la Argentina Alfredo F. Calcagno

Exportaciones de manufacturas: desafíos para las pequeñas economías de América Latina

Rudolf M. Buitelaar, Pitou van Dijck

¿Por qué las inversiones en el transporte público no reducen la congestión de tránsito urbano?

lan Thomson

Nolas sobre la mediclón de la pobreza según el método del ingreso

Juan Carlos Feres

La politica fiscal y el ciclo económico en Chile

Carlos Budnevich, Guillermo Le Fort

Evaluación de la política de bienes de capital en la Argentina

Pablo Sirlin

Reestructuraclón de los grupos industriales brasileños entre 1980 y 1993

Ricardo $M$. Ruiz

Reestructuración productiva y cambio territorial: un segundo eje de Industrlallzación en el norte de México

Tito Alegría, Jorge Carrillo, Jorge Alonso Estrada

Publicaciones recientes de la CEPAL 


\section{Reestructuración productiva \\ $y$ cambio territorial: un segundo eje de industrialización en el norte de México}

\section{Tito Alegría Jorge Carrillo $V$, Jorge Alonso Estrada \\ Investigadores de El Colegio de la Frontera Norte, \\ Tijuana, México.}

En este artículo se plantea que la reestructuración industrial en México se está constituyendo sobre dos ámbitos territoriales diferentes $y$, en cierta medida, con trayectorias de desarrollo independientes: por un lado, un ámbito territorial configurado en torno a la logica de industrialización norteño-fronteriza; por otro lado, el ámbito territorial de la industria implantada durante la fase de la industrialización sustitutiva, concentrado en las zonas metropolitanas del centro de México. A juicio de los autores, se trata de trayectorias de industrialización distintas que operan de manera paralela, con diferentes procesos y formas de organización social de la producción en el territorio; por lo tanto, para eatender el sentido de la reestructuración productiva conviene estudiar las lógicas de los sectores industriales y la del territorio de manera simultánea, ya que el curso de los acontecimientos en torno a la reestructuración industrial pasa por el filtro de las dinámicas regionates y locales. De allf la necesidad de contar con un perfil de cómo se procesan y se producen en este nivel las diversas modalidades de la reestructuracion. Tras una introducción en que se plantean estos temas (sección I), en el artículo se analiza la dinámica industrial reciente, para evaluar el alcance del argumento acerca de la "nortefización" del núcleo dinámico del crecimiento (sección II); se discute la noción de eje funcional-territorial, que permite interpretar la dinámica descrita en el apartado anterior (sección III), y se caracteriza el eje notteño-fronterizo (sección IV) en términos de dos aspectos de su organización social que lo distinguen radicalmente del eje centro: el papel de los gnupos económicos regionales y las características de los mercados regionales de trabajo. 


\section{I}

\section{Introducción}

El desplazamiento del dinamismo industrial de México desde las zonas metropolitanas del centro hacia las ciudades del norte ha sido señalado por diversos estudios como uno de los aspectos más notables de la reorganización de la economía mexicana. Esta "norteñización" del desarrollo industrial del país se ha descrito recurriendo a diversos indicadores, que destacan la relocalización y reorganización de sectores claves (automotriz, electrónico, etc.), los cambios en la dinámica y la estructura de la fuerza de trabajo (De Oliveira y García, 1993), las modificaciones sustantivas en las relaciones laborales asociadas a la relocalización (De la Garza, 1993), o el cambio estructural y el aumento del peso relativo de la industrialización maquiladora fronteriza (González-Aréchiga, 1988; Carrillo, 1989).

A pesar de la precisión de los indicadores y la seriedad de quienes los han utilizado, las interpretaciones del significado de este proceso oscilan entre la suspicacia y la exageración. Por una parte están quienes a partir de una lectura amable reconocen en las características de la industrialización fronteriza y norteña una especie de premonición exitosa del futuro nacional en el contexto de la apertura económica, gracias a una mayor competitividad y la introducción de prácticas y tecnologías de vanguardia. Por otra parte, no son pocos los que arguyen que la nueva industrialización norteña ofrece salarios y condiciones de trabajo precarios, aumenta los riesgos ecológicos, subordina escandalosamente el desarrollo del país a las necesidades de las empresas transnacionales y representa por esto el atisbo de una maldición que se extenderá al resto de México en cuanto las reformas económicas y el Tratado de Libre Comercio de Norteamérica (TLCN) alcancen vuelo suficiente.

En estos tonos -invocados de modo velado, sutil o abierto - se ha perfilado la cuestión regional derivada de la reestructuración industrial en México. Independientemente del contenido de verdad de tales

[.-] Una primera versión de este trabajo se presentó en el Seminario Internacional de Impactos Territoriales de los Procesos de Reestruciuración, organizado por el Instituto de Estudios Urbanos de la Universidad Católica de Chile (Santiago de Chile, 12 al 14 de julio de 1995). interpretaciones, está claro que esa reestructuración industrial opera en un marco de alternativas que aún no han dado todo de sí. Es dudoso, por ejemplo (porque existe evidencia al respecto), que la industrialización fronteriza tienda a hacer más precarios los salarios y las condiciones de trabajo (Carrillo, coord., 1993); pero si se profundiza un poco en los rasgos del proceso de industrialización norteño, queda de manifiesto cuán aventurada es la idea de que éste pueda extenderse al resto de las zonas industriales del país. Como la reestructuración industrial en México es ya generosa en experiencias y datos empíricos, permite evaluar falacias como las aquí señaladas y proponer algunas hipótesis fundamentadas en torno al curso actual del proceso.

Este ensayo busca precisamente abordar tales temas con el ánimo de proponer una interpretación sustentada en el análisis de las características de la industrialización en el norte de México. Basándonos en la investigación acumulada en los últimos años, argumentamos que la reestructuración industrial en México se está dando en dos ámbitos territoriales diferentes y, en cierta medida, con trayectorias de desarrollo independientes. El primero es el ámbito territorial que alberga la industria implantada en la fase de industrialización sustitutiva y que abarca las zonas metropolitanas del centro de México; el segundo es el ámbito territorial configurado en torno a la lógica de industrialización norteño-fronteriza (pues no se trata necesariamente de un ámbito exclusivamente fronterizo).

Nuestra tesis intenta poner en tela de juicio las interpretaciones de los impactos territoriales de la reestructuración que entienden esta reorganización como un proceso unitario tendiente ya sea a la polarización, ya sea a la convergencia. Creemos que en realidad estamos frente a trayectorias de industrialización distintas que operan de manera paralela, con distintos procesos y formas de organización social de la producción en el territorio respectivo. Asimismo, pretendemos disuadir del error de interpretar la reestructuración desde la perspectiva de un sector o rama industrial, dejando de lado los aspectos socioespaciales del proceso. Por el contrario, las trayectorias de desarrollo históricamente ancladas en cada territorio explican en 
gran medida la naturaleza y evolución de los dos ejes de industrialización que caracterizan la reestructuración industrial en México.

Nuestra propuesta, por lo tanto, parte del planteamiento metodológico de que para entender el sentido de la reestructuración productiva hay que estudiar las lógicas de los sectores industriales y la del territorio de manera simultánea. Recurriremos en primer lugar a algunos datos estadísticos acerca del desarrollo industrial reciente, para evaluar el alcance de la tesis acerca de la "norteñización" del núcleo dinámico de crecimiento. En segundo lugar, examinaremos la noción de eje funcional-territorial, con el fin de proponer criterios que nos permitan interpretar el sentido del proceso descrito. Por último, describiremos el eje norteño-fronterizo en términos de dos aspectos de su organización social que lo distinguen radicalmente del eje centro: el papel de sus grupos económicos y las características de sus mercados de trabajo. Utilizaremos los conceptos de regulación mesoeconómica y regulación microeconómica para referirnos a uno y otro de dichos aspectos.

\section{II}

\section{Patrones territoriales en la configuración del}

\section{nuevo núcleo dinámico de la industrialización}

en México

La primera tarea que surge al abordar la "norteñizacion" de la nueva industrialización mexicana es la de estimar su magnitud, ya que aún son pocos los esfuerzos hechos por conocer empíricamente y de manera amplia el alcance de la industrialización norteño-fronteriza reciente. En este apartado se presenta un esfuerzo modesto, aunque bastante revelador, al respecto. Utilizamos datos sobre empleo industrial de los censos económicos de 1980 y 1993 (INEGI, 1983 y 1995). Los años censales son importantes, pues corresponden aproximadamente a levantamientos en dos momentos altos del ciclo económico nacional: el de 1980 y el de 1993. El primero corresponde a la parte alta del ciclo inmediatamente anterior a la intensificación del proceso reestructurador iniciado con la crisis de 1982 . Y el segundo es previo al punto alto del ciclo que terminó precisamente con la crisis financiera de diciembre de 1994. Aunque esta información no recoge toda la riqueza de un proceso que ba sido bastante dinámico, sin embargo constituye un indicador útíl.

Para defínir lo que hemos denominado el núcleo dinámico de la industrializacion, es decir, las clases industriales responsables del incremento absoluto en el empleo industrial entre 1980 y 1993 , identificamos en la clasificación mexicana a cuatro dígitos las ramas que más habían acrecentado el empleo industrial entre esas dos fechas; en conjunto, las ramas que incrementaron su empleo absoluto acumularon un total de 1130140 empleos. El núcleo dinámico está constituido por las diez ramas que ganaron más empleo y que son responsables del $57 \%$ de la diferencia absoluta entre el empleo industrial de 1980 y el de 1993. La rama de maquinaria y equipo eléctrico (3831) fue la más dinámica y por sí sola gener 6 el $10.4 \%$ de esa diferencia. Por otra parte, la pérdida absoluta en las ramas que disminuyeron su participación fue de 85206 empleos, correspondiéndole más de la mitad de esa cifra a la industria básica del hierro y el acero (43 347 empleos). Es interesante señalar que de la clasificacion industrial a cuatro dígitos sólo esas diez ramas disminuyeron su participación, mientras que el resto la mejoro. ${ }^{1}$

Una vez definido de este modo el núcleo dinámico de la reestructuración industrial, nuestro interés se centra en determinar el patrón territorial de ese dinamismo. El mapa 1 muestra la distribución del crecimiento absoluto del empleo industrial entre 1980 y 1993, por estados. Lo primero que salta a la vista en el mapa es que hay dos amplias zonas geográficas de

\footnotetext{
1 Es importante señalar que este tipo de análisis deja de lado el efecto del peso relativo de las diversas ramas, y subraya su participación en el crecimiento. Sin embargo, sólo detectamos una rama que a pesar de tener peso relativo importante en ambos perfodos perdió dinamismo: la de hilados y tejidos de fibras blandas (rama 3212), que representaba un 5.3\% del total de empleo industrial en 1980 (con 112812 empleos) y que, debido a su pobre desempeño, en 1993 bajo esa cifra a $3.6 \%$ (con 115788 empleos)
} 
MAPA I

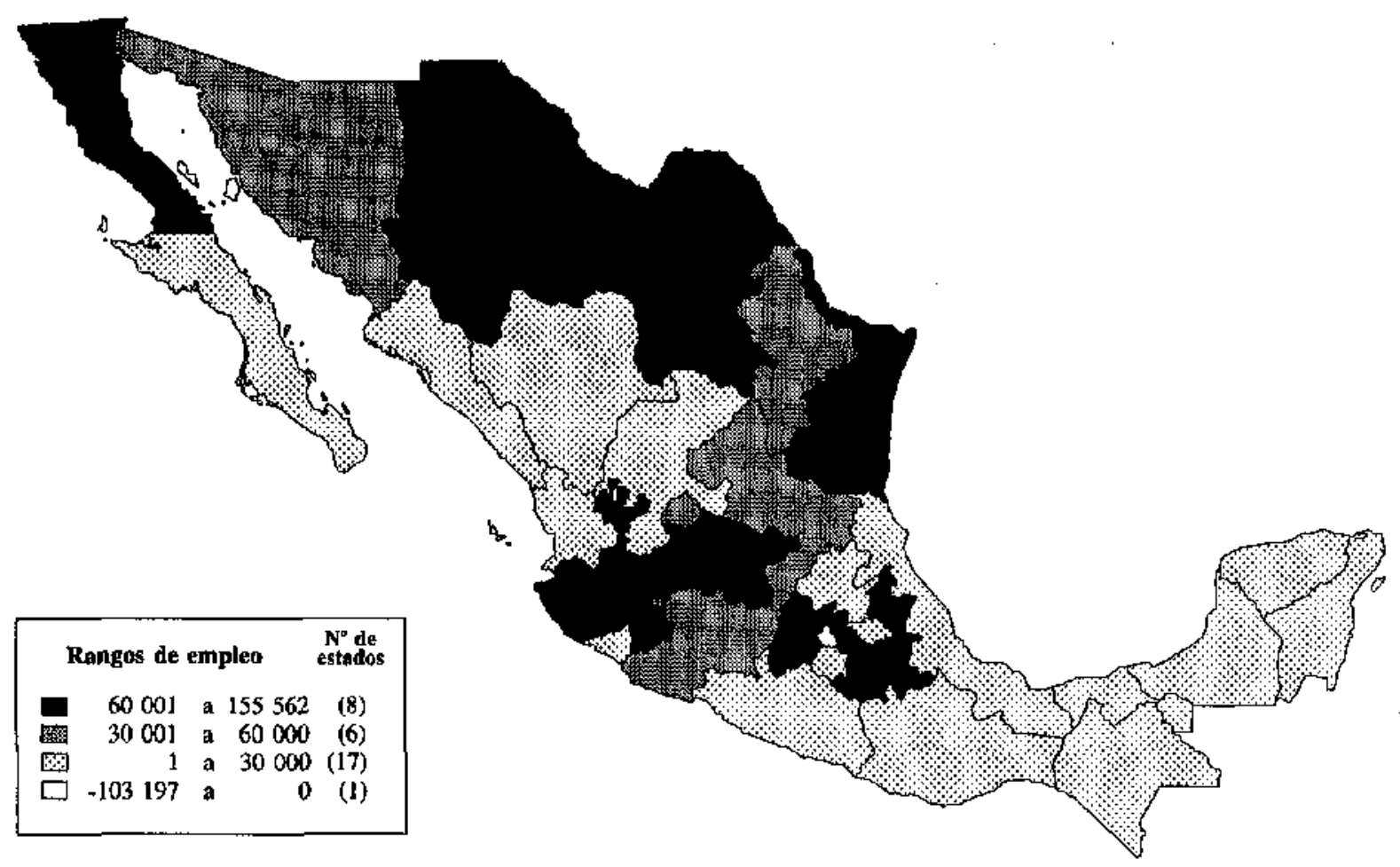

crecimiento: los estados del norte asociados al crecimiento de la industria maquiladora y a nuevas operaciones exportadoras, y los estados del centro de México asociados históricamente al crecimiento industrial basado en el viejo modelo sustitutivo de importaciones, y sometidos a un intenso proceso de reestructuración con vistas al nuevo modelo exportador y de apertura comercial. Cabe señalar que entre 1980 y 1993 los estados norteño-fronterizos, excluido Nuevo León, que siendo norteño ha estado histórica y funcionalmente asociado al patrón de crecimiento del modelo sustitutivo, generaron $39.3 \%$ del nuevo empleo industrial.

De estos datos se puede desprender que aunque el crecimiento relativo ha sido significativamente superior en los estados del norte, en el eje tradicional del crecimiento industrial (con la notable excepción del Distrito Federal, único perdedor) los estados de Nuevo León, Jalisco, Estado de México, Puebla y Guanajuato mantuvieron su crecimiento y protagonismo en el período analizado, a pesar de la dureza del proceso de reestructuración que los afectó.

Sin embargo, es necesario contar con un indicador más preciso que permita definir las tendencias en la distribución territorial del dinamismo industrial. ¿Se trata de una tendencia a la "norteñizacion" de la indus. trialización nacional, o de un proceso con caracterfsticas diferentes? Para evaluar esta cuestión utilizamos como referencia el grado de concentración industrial que los estados y el Distrito Federal exhibían en 1980, con el fin de analizar esa distribución inicial en relación con las diferencias de empleo absoluto que mostraron estas entidades federativas entre 1980 y 1993.

Existe una manera sencilla de producir un indicador para este análisis; es la de relacionar la variación absoluta del empleo industrial en las entidades federativas entre 1980 y 1993 con la participación de cada una de ellas en el empleo industrial de 1980 (gráfico 1). Si ubicamos a esas entidades en el eje horizontal según su participación porcentual en el empleo industrial en 1980, y colocamos en el eje vertical las diferencias absolutas de empleo entre 1980 y 1993, se observa que la línea de regresión entre ambas variables (excluyendo el Distrito Federal) tiene pendiente positiva. Esto implica que tiende a mantenerse el viejo patrón de concentración territorial en los estados del eje centro. La excepción es el Distrito Federal (es decir, la zona metropolitana de la ciudad de México), que rompe radicalmente el esquema al ser la única entidad federativa que pierde empleo absoluto. 
GRAFICO

México: Cambio en el empleo industrial, por estados," entre 1980 y 1993

Empleos (miles)

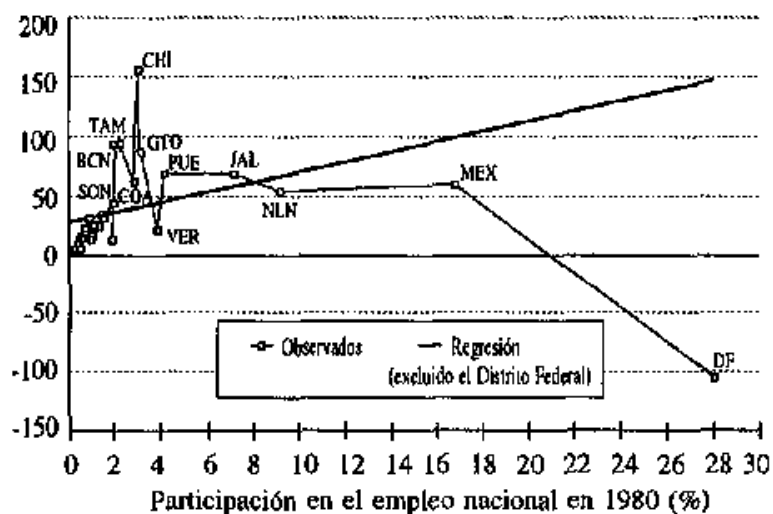

- Sonora, Baja California, Tamaulipas, Chihuahua, Guanajuato, Coahuila, Veracruz y Puebla, Jalisco, Nuevo León, Estado de México y Distrito Federal

Por otra parte, la industrialización mexicana reciente se concentra en los estados norteño-fronterizos, ${ }^{2}$ pero también en otros del centro del país, notablemente Guanajuato y Puebla, y Jalisco. De este modo, podemos decir que si bien la dispersión del dinamismo industrial benefició en gran medida a los estados norteño-fronterizos, en el centro del país la pérdida de dinamismo del Distrito Federal se acompañó de una dispersión entre los estados de la zona, incluidos aquellos que tuvieron una considerable participación en 1980, como Nuevo León y el Estado de México. En definitiva, se ha modificado significativamente el patrón de concentración geográfica de la industria, aunque sin cambios drásticos de posición de los estados más gravitantes (gráfico 2).

Por último, nos interesa analizar si lo que señalamos respecto a las diferencias totales de empleo entre 1980 y 1993 se aplica también al núcleo dinámico (grafico 3). Los resultados son interesantes y confirman la tendencia anterior. A pesar de la heterogeneidad de comportamientos, casi todos los sectores presentan diferentes grados de una "distribución bimodal" del crecimiento: es decir, crecimiento significativo en áreas que no mostraban concentración industrial en el período de sustitución de importaciones, pero también crecimiento en áreas de alta concentración asociadas al viejo patron territorial (distorsionado en un extremo por el desempefio negativo del Distrito Federal). Por ejemplo, en los casos de estructuras metálicas (rama

${ }^{2}$ Los estados de Baja California, Sonora, Chihuahua, Coahuila y Tarnaulipas.
GRAFICO 2

Máxico: Participación en el empleo industrial, por estados," en 1980 y 1993

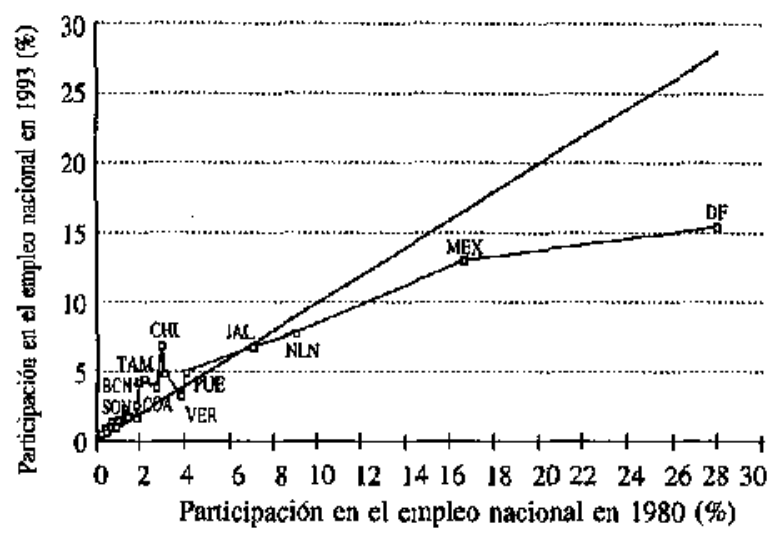

' Sonora, Baja California, Tamaulipas, Cohauila, Chihuahua, Guanajuato, Verncruz, Puebla, Jalisco, Nuevo León. Estado de México y Distrito Federal

3811), productos lácteos (rama 3112), productos plásticos (rama 3560) e industria automotriz (rama 3841), la distribución es pronunciadamente bimodal (aunque el factor Distrito Federal tiende a distorsionar el efecto). El caso de la industria automotriz es relevante (mapa 2) porque suele tomarse como referencia en el estudio de la relocalización de plantas ensambladoras y de autopartes en México (Arteaga, coord., 1993; Carrillo, ed., 1990; Mortimore, 1995); muestra además que pese a haber emergido el crecimiento asociado a la lógica norteña, las zonas del centro del pafs mantuvieron un dinamismo comparable. No ocurre lo mismo en la industria de equipo electrónico, radio y televisión (rama 3832); en este caso los estados norteños que ya concentraban porcentajes importantes del sector mantuvieron su dinamismo, mientras que el Distrito Federal y el Estado de México, que habían concentrado porcentajes similares, se desplomaron radicalmente.

Estos resultados permiten delinear con más precisión la supuesta "norteñización" del crecimiento industrial reciente en México. Desde nuestro punto de vista, en realidad se trata de la emergencia de un nuevo eje de crecimiento, ciertamente muy dinámico; pero no puede descartarse que la reconversión haya implicado también crecimiento en el eje tradicional de la industrialización mexicana. La excepción es el Distrito Federal, cuya pérdida de empleo es sin lugar a dudas significativa (103 197 ocupaciones), pero que en la actualidad aún concentra un porcentaje importante del empleo industrial (15.5\% en 1993, habiendo sido de $25.5 \%$ en 1980 ). 
GRAFICO 3

México: Camblos en el empleo en algunas ramas industriales, 1980-1993

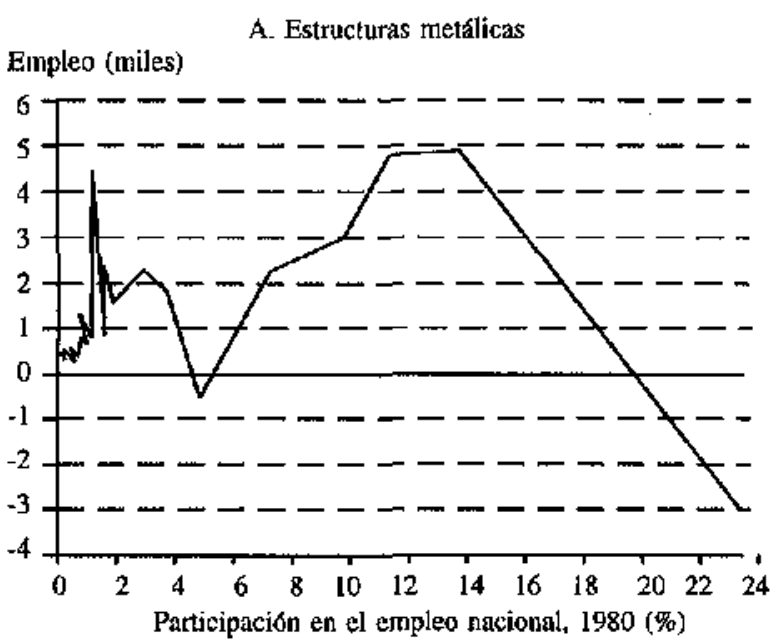

\section{B. Productos lícteos}

Empleo (miles)

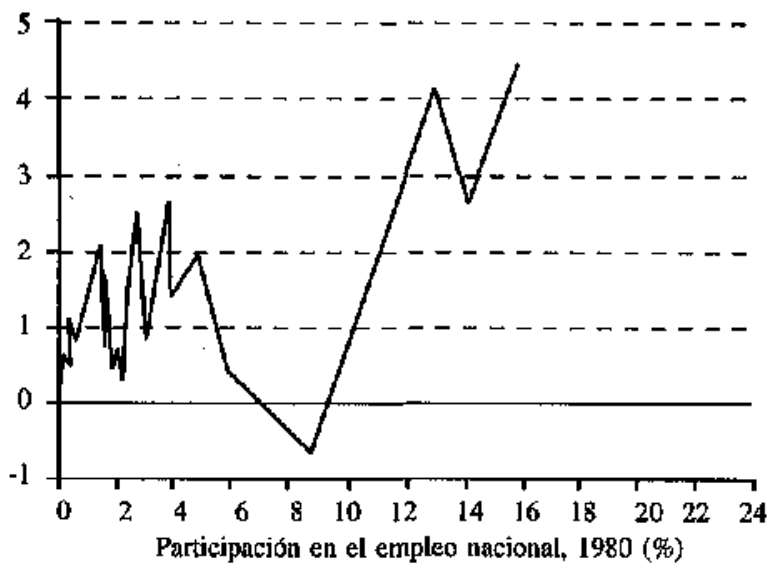

D. Equipo electrónico

Empleo (miles)

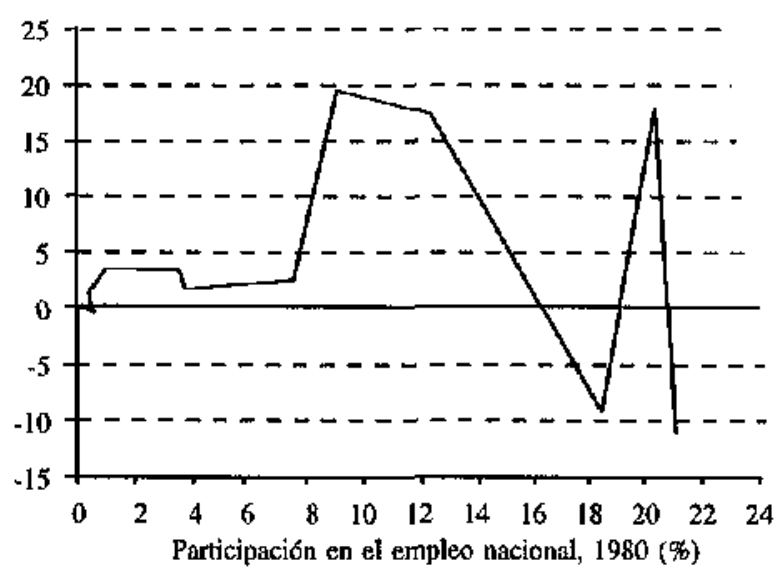

F. Maquinaria eléctrica

Empleo (miles)

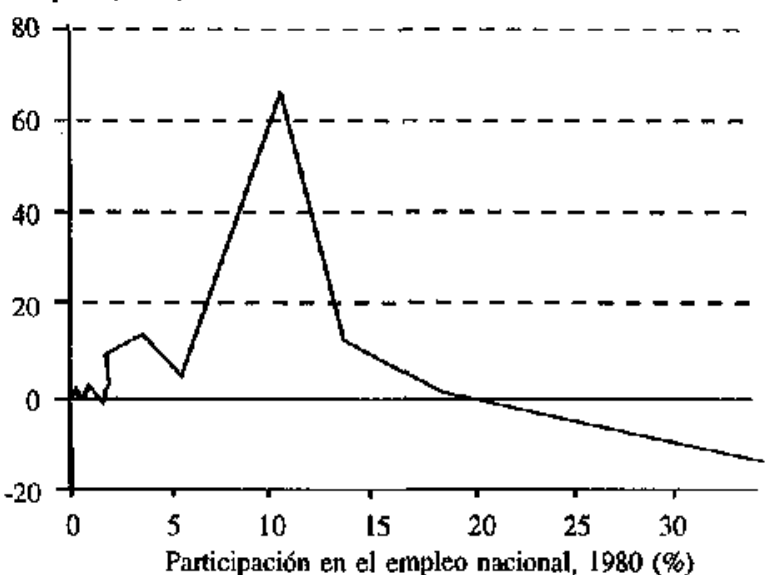

Participación en el empleo nacional, 1980 (\%)

Participación en el empleo nacional, 1980 (\%)
Empleo (Iniles)

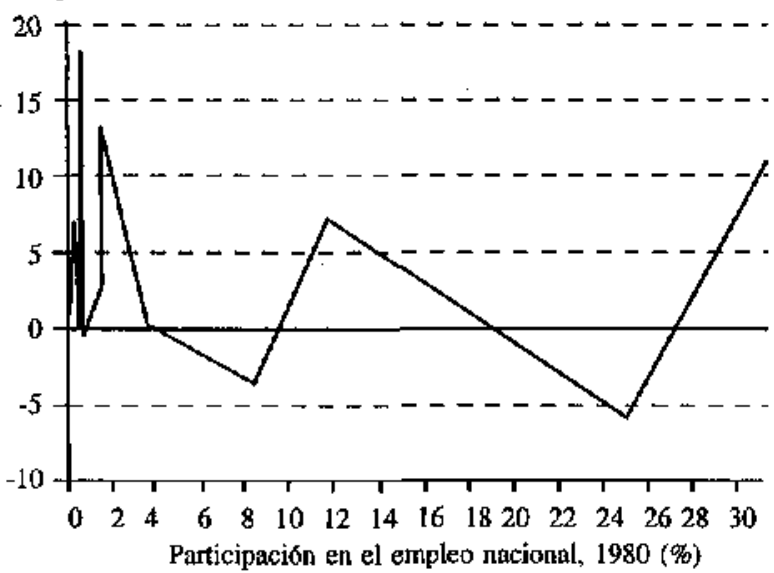

Empleo (miles)

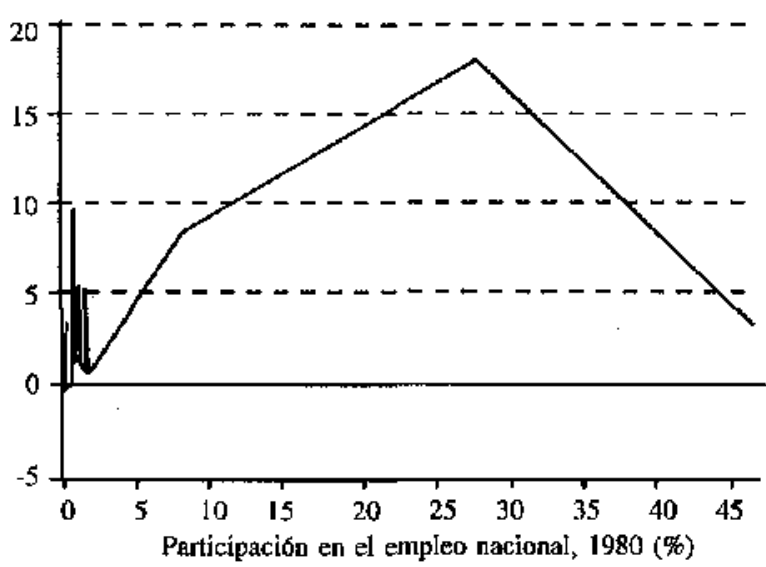

E. Industria automatriz

C. Productos de plástico 
MAPA 2

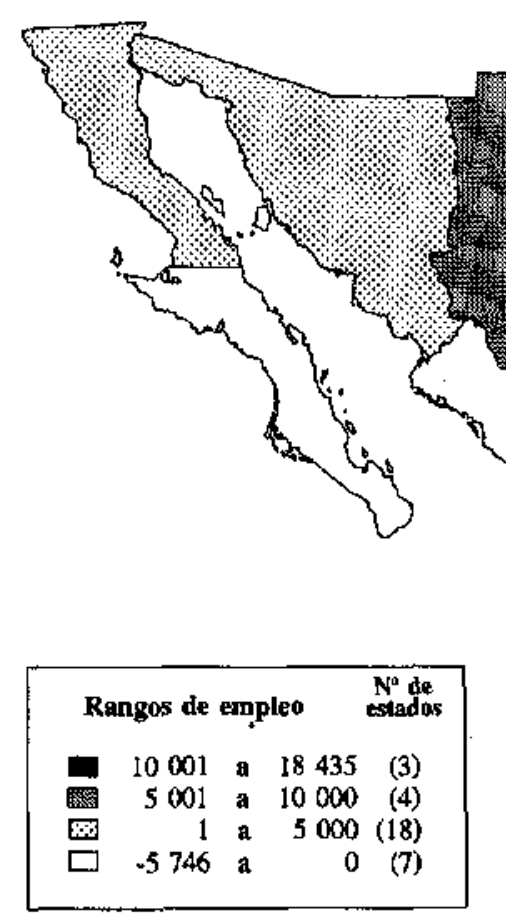

En todo caso, se puede suponer que la reconversion en el eje geográfico históricamente asociado al desarrollo industrial mexicano le ha permitido mantener su papel protagónico en el contexto de la industrialización, reforzado por una tendencia a la dispersion del crecimiento industrial en su interior (por ejemplo, en Puebla y Guanajuato). Si se utilizan las tasas de crecimiento como principal elemento de análisis, podría pensarse que el eje norteño-fronterizo tiende a preponderar en la dinámica de crecimiento, dado que presenta las tasas más altas. Pero es importante subrayar que los cambios dependerán del desarrollo que logren los sectores reestructurados del centro del país en los próximos años, puesto que las lógicas funcional-territoriales en uno y otro eje operan en momentos muy diferentes de sus respectivos procesos expansivos. Aunque en este caso los números tienen importancia, lo más relevante es entender las logicas sociales que explican su respectivo crecimiento. ${ }^{3}$

\section{III}

\section{Los dos ejes funcional-territoriales en la} reestructuración industrial mexicana

El análisis cuantitativo sólo refleja una parte de la historia: efectivamente, la expansión norteño-fronteriza representa la emergencia y consolidación de un segundo ámbito espacial del crecimiento industrial reciente. Sin embargo, lo que nos interesa mostrar es que no se trata de un simple desplazamiento del crecimiento in- dustrial de un punto a otro del territorio, es decir, que no es un fenómeno estrictamente de distribuición espa-

\footnotetext{
${ }^{3}$ No bay que olvidar que el eje norteño-fronterizo responde a una logica de despegue, mientras que en el eje centro ésta se combina con la lógica de reconversión (por ejemplo, en Aguascalientes).
} 
cial. De lo que se trata es de dos configuraciones distintas de la organización del desarrollo industrial, que coexisten bajo el manto protector del mismo modelo de gobernación macroeconómica. Por otra parte, las características de las ramas que constituyen el núcleo dinámico de la industrialización reciente adquieren particularidades de organización radicalmente distintas según pertenezcan a uno u otro eje; en otras palabras, el proceso no es estrictamente sectorial.

Recurrimos al concepto de eje funcional-territorial para enfatizar la necesidad de incluir en un solo marco analítico la dinámica del sector, rama o producto industrial, y la de las configuraciones territoriales. ${ }^{4}$ Podemos definir este concepto como el conjunto de trayectorias de cambio organizacional y productivo adquiridas por el desartollo de un núcleo dinámico de industrialización, en el marco de interdependencias territoriales expresadas en una serie de convenciones e instituciones de gobernación economica. En otras palabras, el desarrollo industrial se configura sobre las bases de una relación estrecha con la configuración organizacional de los espacios en los que se expresa, y permanece anclado históricamente.

El concepto de gobernación económica ${ }^{5}$ se utiliza aquí para indicar cierto proceso común en las diferentes trayectorias de cambio que adquiere el núcleo dinámico de la industrialización. Es decir, la heterogeneidad de los desenlaces, expresada por ejemplo en una diversidad de sistemas productivos regionales, tiene como contrapartida un horizonte común de modalidades de coordinación económica (y de lucha por su definición y cambio); en este horizonte común están, por ejemplo, las relaciones y estrategias de los grupos económicos dominantes, las caracteristicas de las relaciones intrafirma e interfirmas, el sistema de relaciones industriales y otros aspectos. Este ámbito común, insistimos, es un atributo del eje, y se expresa con particularidades propias en cada sistema productivo regional, o en cada sector, rama o cadena de producción que lo constituye.

Un aspecto determinante de la gobernación económica en el núcleo dinámico de la industrialización se presenta a nivel macro: se trata del modelo de política económica y de desarrollo nacional, $y$ las formas

\footnotetext{
${ }^{4}$ La idea de eje funcional-territorial debe entenderse como una bertamienta conceptual, y en este sentido, toda elaboracion sustantiva que de esta idea se desprenda (por ejemplo, la idea de un eje norteño-fronterizo en México) debe entenderse como un "tịn ideal." ${ }^{5}$ Entendido como las instituciones, convenciones, prácticas y procesos de coordinacion que producen y reproducen los agentes económicos para garantizar el desempeño exitoso de su intervención. Véase Campbell y Lindbergh (1991) y Stoper y Harrison (1990).
}

de coordinación internacional que expresa. Lo particular en el caso mexicano es que si bien durante el desarrolto estabilizador existió un solo eje funcional-territorial de industrialización, el nuevo modelo generó la expansión y evolución cualitativa de un cje que durante el período previo se había mantenido como un ámbito periférico al núcleo dinámico: el eje de industrialización caracterizado por la industria maquiladora de exportación en la zonas fronterizas del norte de México. A este proceso se asoció la cxpansión de las operaciones manufactureras para la exportación realizadas por empresas trasnacionales, que desde finales de los años setenta encontraron en el norte del país un ámbito ideal para su instalación. En el eje centro, por su parte, hubo un intenso proceso de reestructuración industrial que históricamente había caracterizado el desarrollo de la industrialización mexicana. Las diferencias fundamentales entre estos dos cjes, por lo tanto, no se encuentran a nivel de la gobernación macroeconómica. Aunque debido a las características particulares de uno y otro los efectos de la medidas de política económica (como las cambiarias) son muy diferentes, cada eje tiene su propia lógica organizacional y productiva frente al mismo modelo de política económica. $^{6}$

Las diferencias fundamentales entre ambos ejes se encuentran en los niveles meso y micro de su gobernación económica. La regulación mesoeconómica se refiere al nivel de configuración organizacional en que actúan los grupos económicos u organizaciones empresariales para mantener, modificar o generar un marco de regulación económica concordante con sus orientaciones estratégicas para la expansión y el desarrollo. La regulación microeconómica se refiere al nivel de configuración organizacional en que se dirimen los aspectos operacionales de los procesos productivos (por ejemplo, las relaciones intrafirma e interfirmas) y de los mercados locales de trabajo, así como aspectos tecnológicos y de desempeño productivo.

Aunque un examen exhaustivo de ambos ejes rebasaría los límites de este trabajo, ${ }^{7}$ que busca analizar el eje norteño-fronterizo, cxpondremos brevemente algunas radicales diferencias entre ellos.

\footnotetext{
- Una tarea importante en esta perspectiva de análisis, y que desafortunadamente no podemos emprender aquí, consiste precisamente en evaluar el diferente impacto de las diversas medidas de política económica en ambos ejes, para saber si surgen necesidades contradictorias debido a la naturaleza de sus respectivas trayectorias de desarnollo, o si dicha política ha podido mantener un balance apropiado para sostener ambas trayectorias.

${ }^{7}$ Ese examen, así como un análisis más pormenorizado del concepto de eje funcional-territorial, se encuentra en Alonso (1996).
} 
En lo que se refiere a la gobernación mesoeconómica, en el eje centro son las orientaciones estratégicas de los grandes grupos oligopólicos nacionales las que determinan el sentido de la intervención que realizan para inducir cambios en el marco regulatorio de su núcleo dinámico. La conformación misma de esos grupos durante el período de desarrollo estabilizador y el de sustitución de impottaciones les otorgó un carácter nacional, no obstante estar anclados en diferentes ámbitos territoriales (zona metropolitana de la civdad de México, Guadalajara, Puebla y Monterrey). Las intervenciones de tales grupos continúan siendo de alcance nacional y, en cierta medida, el surgimiento en México del nuevo modelo secundario exportador está asociado al desenlace del conflicto entre dichos grupos por definir el curso y las características de la regulación económica nacional. ${ }^{8}$

En el eje norteño-fronterizo, en cambio, los grupos económicos asociados a la emergencia y consolidación de su marco regulatorio casi no perdieron su carácter regional, aunque disputaron de manera individual (como el Grupo Chihuahua) o colectiva (como las asociaciones industriales fronterizas) un espacio propio en el marco de la estrategia nacional de desarrollo industrial.

En el ámbito de la gobernación microeconómica las distinciones son aún más radicales. El desarrollo del modelo sustitutivo de importaciones genero en el eje centro una configuración productiva y de relaciones industriales que podríamos caracterizar como cuasi fordista: producción en masa para consumo nacional, eslabonamientos productivos nacionales estables, un sistema de relaciones industriales con prerrogativas para el trabajo (negociación colectiva). La reestructuración de este eje significó un cambio radical en las particularidades de estos aspectos, pero su evolución mantuvo la misma trayectoria: producción para el mercado nacional, pero bajo un modelo de apertura comercial y con orientaciones fuertes a la exportación; fortalecimiento de los eslabonamientos productivos nacionales de carácter competitivo, pero sustitución por insumos importados de aquellos que no cumplen con los requisitos de competitividad; debilitamiento de los sindicatos y de las prerrogativas del trabajo, pero mantenimiento de la negociación colectiva.

El eje norteño-fronterizo, en cambio, operó desde sus inicios con una lógica de despegue, sin organizaciones sindicales efectivas (salvo casos excepcionales como el de Tamaulipas), casi sin eslabonamientos productivos nacionales y con condiciones de operacion diferentes de las de los mercados locales de trabajo (por ejemplo, empleo mayoritario de mujeres).

Sin embargo, la diferencia más radical entre ambos ejes es la continuidad o discontinuidad entre la gobernación mesoeconómica y la microeconómica. En el eje centro, los empresarios que controlan los grupos oligopólicos nacionales controlan también la orientación estratégica de los procesos productivos en las firmas; en el eje norteño-fronterizo, dicho control lo ejercen las empresas transnacionales como parte de sus orientaciones estratégicas, mientras que los empresarios de la region se limitan a generar y mantener el marco regulatorio y a facilitar servicios e infraestructura industrial. $Y$ en la gobernación microeconómica de su orientación productiva incluso las empresas transnacionales que operan en uno y otro eje actúan de manera estratégica diferente.

Aunque este trabajo está enfocado al examen del surgimiento y consolidación del eje norteño-fronterizo, es importante subrayar aquí que el concepto de eje funcional-territorial intenta darle sentido a una segmentación decisiva ocurrida en la industrialización nacional, y poner de relieve la emergencia de dos lógicas de gobernación mesoeconómica y microeconómica que operan de manera paralela, con pocos vínculos productivos entre sí, y bajo un mismo modelo de política económica y de desarrollo.

\section{Eje norteño-fronterizo: la regulación económica}

\section{de la nueva industrialización}

\footnotetext{
${ }^{8}$ Por regulación econónica entendemos los procedimientos y reglas formales instituidos con el propósito de ajustar y condicionar la conducta de los agentes a un fin preestablecido.
}

\section{Surgimiento de este segundo eje}

La nueva incustrialización norteño-fronteriza de México partió con un conjunto de actividades industriales 
que emergieron bajo los auspicios del régimen de importación temporal para la exportación establecido a mediados de los años sesenta, a las que suele agruparse bajo la denominación de industria maquiladora de exportación (IME) fronteriza. En el contexto nacional, dicha industrialización fue tardía y atípica respecto del modelo dominante, el de sustitución de importaciones. La industrialización de México iniciada en los años treinta se caracterizo por una alta concentración territorial en la ciudades de Guadalajara, Monterrey, Puebla y, sobre todo, en la zona metropolitana de la ciudad de México, las que corresponden a la configuración histórica del eje centro. La política que le dio origen estaba plenamente encuadrada en el modelo sustitutivo de importaciones, era altamente proteccionista y estaba orientada a satisfacer las prioridades del mercado interno.

La industria norteño-fronteriza se estableció en un territorio con sobreoferta de mano de obra y escasez de empleos. Debido a modificaciones en el sector agrícola y a los flujos migratorios procedentes del sur, la región experimentó un crecimiento demográfico que fue más allá de su capacidad de absorber fuerza de trabajo. Entre 1940 y 1960 la población se duplicó y en consecuencia la región enfrentó serios problemas en materia de empleo, vivienda y servicios urbanos. Además, la cancelación por los Estados Unidos del convenio binacional de braceros en 1964 obligó a la repatriación masiva de trabajadores mexicanos, muchos de los cuales decidieron establecerse en la zona fronteriza mexicana.

Es en este contexto que debe entenderse el establecimiento del Programa de Industrialización Fronteriza en 1965, mediante el cual se permitió y alentó la instalación de plantas maquiladoras para la exportación, de manera excepcional y subordinada a la industrialización sustitutiva. Con esto el gobierno mexicano, retomando algunas experiencias incipientes de zonas de procesamiento para la exportación en otros países, iniciaba una política de excepción, con alcances temporales y geográficos bien delimitados. Se pretendía que en el mediano plazo el impulso industriatizador generara eslabonamientos productivos que alentaran una industrialización de base nacional, a través de la cual la región fronteriza se podría "reintegrar" a la economía nacional. En cuanto a su alcance geográfico, el modelo respondía exclusivamente a las condiciones excepcionales de la frontera norte en lo que se referra a su mercado laboral y a su cercanía con los Estados Unidos.

Ante la preeminencia del modelo sustitutivo de importaciones, la IME aparecía como un fenómeno eminentemente periférico, tanto por la magnitud que representaba en el contexto mexicano como por la intención misma de la política gubernamental que lo apoyaba. Pero la crisis de 1982 significó una ruptura con aquel enfoque. Ese año presenci 6 el despegue decisivo del desarrollo industrial fronterizo, gracias a los efectos que tuvo la intensificación de la competencia mundial en la economía estadounidense, y sobre todo, a las medidas de política macroeconómica adoptadas por México para consolidar el modelo de industrialización exportadora. La industrialización fronteriza dejó de ser un proceso periférico. Desde 1970 el empleo en el eje norteño-fronterizo ha crecido anualmente en un $10 \%$, en contraste con un $2 \%$ en la industria manufacturera nacional. Hoy, con cerca de 3500 establecimientos y 750000 empleos, puede decirse que la IME, en conjunción con las plantas manufactureras de exportación norteñas, han configurado un segundo eje funcional-territorial de desarrollo industrial en el país, cuyo núcleo se halla en algunas pocas localidades fronterizas.

Del mismo modo, desde finales de los años setenta las empresas transnacionales que operaban en México, sobre todo en sectores donde se había intensificado la competencia internacional (como la tama automotriz), decidieron establecer plantas exportadoras en el norte del país, con el fin de articular una estrategia de producción compartida con sus operaciones en los Estados Unidos. La apertura comercial y las nuevas medidas de política económica orientadas a fomentar la exportación intensificaron este proceso, y a su vez generaron las condiciones para que surgieran operaciones manufactureras (por ejemplo, producción de televisores) de otras empresas transnacionales, que encontraban en la localización norteño-fronteriza y en las modalidades de organización productiva allí existentes un ámbito que facilitaba sus estrategias de expansión. A finales de los años ochenta, la convergencia de las acciones descritas del gobierno y de las empresas transnacionales estaba perfectamente consolidada en lo que hemos denominado el eje norteñofronterizo de la industrialización nacional.

No fue éste un simple proceso de expansión industrial, sino de aparición de operaciones manufactureras y de ensamblaje en las ramas que forman el núcleo dinámico de la industrialización nacional. Los dos casos emblemáticos de este proceso son la industria de componentes electrónicos y bienes electrónicos de consumo y la industria automotriz y de autopartes. En ambos casos el dinamismo e importancia de la expansión industrial y la emergencia de niveles de competitividad global están asociados principalmente a la evo- 
lución de dichos sectores en el eje norteño-fronterizo y, de manera mucho más limitada, en el eje centro. Aun dentro de una misma firma (por ejemplo, Ford) llegan a coexistir las lógicas organizacionales y productivas de uno y otro eje (Carrillo, 1995), lo que se expresa en trayectorias diferentes dentro del núcleo dinámico.

\section{La gobernación mesoeconómica: los empresa- ríos y la gestión del marco institucional}

La emergencia de la industria maquiladora en la frontera norte no fue el simple resultado de una política gubernamental, es decir, de la serie de decretos presidenciales que permitieron mantener una política de industrialización de excepción en las zonas fronterizas, posteriormente ampliada al resto de México. Contribuyeron también las condiciones locales $\mathrm{y}$, sobre todo, los agentes económicos que definieron su dinamismo y el perfil que el crecimiento trajo consigo. El surgimiento de un sector empresarial asociado a dicho crecimiento es fundamental para entender el impacto $y$ las potencialidades de la industrialización maquiladora norteña. Esto porque los grupos empresariales zonales contribuyeron al proceso de integración de la zona al transferir excedentes de un sector a otro dentro de ella a través de la cartera de inversiones y la configuración organizacional. Y aunque dichos grupos no fueron los agentes determinantes del proceso productivo, y en muchos casos permanecen ajenos a él o fungen como propietarios simbólicos de las empresas maquiladoras, la evolución del proceso no estuvo ajena a sus intereses estratégicos en dichas regiones.

Es importante entender la actuación de los grupos económicos de la zona norteño-fronteriza en la promoción de las actividades maquiladoras y de las plantas exportadoras (en general filiales de empresas transnacionales), y también la forma en que tales actividades se incorporan a la lógica organizacional y la estructura de oportunidades en los diferentes sectores de la economía de la zona. Cabe destacar aquí que el sector empresarial ha desempeñado un papel decisivo en la configuración funcional-territorial del eje norteño-fronterizo a través de su intermediación para la configuración institucional, es decir, la gestión de la política de desarrollo fronterizo, y su papel como instancia de organización del conjunto de la economía zonal.

El origen del sector empresarial de la zona estuvo precisamente en el régimen de excepción físcal fronterizo establecido en los anios treinta, pues él permitió el crecimiento del sector comercial y de servi- cios que hasta la fecha genera allí buena parte de la dinámica económica. Fue precisamente en los centros urbanos fronterizos que más se habían desarrollado al amparo de esas políticas, especialmente Tijuana y Ciudad Juárez, donde hubo un mayor crecimiento de la industria maquiladora.

Los regímenes de excepción fiscal para la importación y exportación fronteriza (denominados también de "zona libre") tuvieron gran importancia en el desa. rrollo del eje notteffo-fronterizo. La importación comercial para consumo fronterizo fue esencial para el empresariado de la zona. De hecho, dichos regímenes fungieron como principal modo de acumulación, principalmente porque los productores nacionales (es decir, los grandes grupos oligopolicos mexicanos) no podían competir con las importaciones en los mercados fronterizos por problemas de calidad y precio. Esto significó una contradicción permanente entre el modelo sustitutivo de importaciones y estos regimenes de excepción; en otras palabras, entre los empresarios fronterizos y los grandes grupos oligopólicos nacionales. Tal contradicción se planté en su momento en los términos de una ya histórica controversia de enorme carga ideológica: o fomentar la "integración nacional" de la frontera, o fomentar el "desarrollo regional" de estas zonas. Es de general conocimiento que el primer objetivo orientó las modalidades de intervención económica del gobierno federal en la frontera, en un clima de permanente tensión con el empresariado de la zona.

Por esta razón, las relaciones entre los empresarios fronterizos y el gobierno federal tienen una larga tradición de tensiones y conflictos. El régimen de zona libre se convirtió en el problema central en la relación empresarios-gobierno a mediados de los años cincuenta, momento en que empezó a tener repercusiones regionales la conjunción de una política proteccionista que restringfa la importación y de un tipo de cambio con sobrevaluación que estimulaba el consumo externo. Esta situación caracterizó a la política nacional de industrialización sustitutiva de las importaciones durante el proceso de desarrollo estabilizador.

Es precisamente este conflicto el que en el pasado dio pie a cierta unidad de acción colectiva en el empresariado fronterizo. Durante el período de sustitución de importaciones, la política de desarrollo que el gobierno federal mantuvo respecto de las zonas fronterizas, y la disputa en torno al régimen de zonas libres, se concibio a partir de una fundamental contraposición de intereses entre los grupos económicos fronterizos y los grupos principales a nivel nacional, ubicados sobre todo en las grandes áreas metropolitanas 
del país y que incluían grupos monopólicos nacionales y extranjeros.

Así, la disputa en torno al régimen de zonas libres era sobre todo un conflicto entre grupos económicos, en el cual el Estado intervenfa como mediador ante diferencias entre ellos mismos, y como gestor de la regulación de la competencia capitalista. En cl perfil concreto de la política económica fronteriza se reflejaba la correlación de fuerzas que existía entre los diversos grupos empresariales, el espacio de concertación que el ciclo de la acumulación de capital permitía para concertar intereses, así como la capacidad del Estado para codificar, en la regulación de dicha competencia, un acuerdo satisfactorio para el conjunto de los grupos económicos.

La naturaleza de este conflicto cambió sustancialmente después de la crisis de 1982. Tres elementos estructurales explican este cambio. Primero, la política de subvaluación del peso frente al dólar hizo a los productos nacionales más competitivos frente a la importación fronteriza, to que permitió el establecimiento de cadenas de comercio nacionales y de garant́as para la estabilidad del flujo de abasto del centro a la frontera. Segundo, la política de apertura comercial, aunque trajo problemas inmediatos en la gestión de las zonas libres, fue creando un marco favorable para que los grupos regionales invirtieran con visión de largo plazo en los diferentes sectores de la economía, sobre todo en los servicios y la manufactura. Tercero, en la medida en que la generación de divisas extranjeras se convirtió en una prioridad del modelo mexicano, se fortaleció la política de apoyo a la IME, lo que garantizó una expansión notable de las actividades empresariales norteño-fronterizas asociadas a la industria maquiladora (servicios profesionales, gestión industrial, construcción', renta de infraestructura, etc.).

Un segundo grupo importante del sector empresarial norteño-fronterizo lo constituyeron los industriales cuyos mercados eran fundamentalmente sus entornos zonales pero que mantuvieron orientaciones estratégicas para penetrar en los grandes mercados nacionales. ${ }^{9}$ En todo caso, dichos grupos tuvieron un papel activo en la promoción de la nueva industrialización exportadora, sobre todo con el fin de fortalecer su posición de conformidad con sus estrategias de crecimiento.

\footnotetext{
${ }^{9}$ Excepcional es el caso del Grupo Chihuahua, que en deterninado momento alcanzó niveles comparables con otros grupos nacionales, y que hoy mantiene una orientación estratégica hacia la exportación y hacia la penetración de los mercados zonales.
}

Es dificil prever el nivel de éxito que alcanzarán dichos grupos en el futuro inmediato, aunque el proceso de nueva industrialización resulte ventajoso para al menos algunos de ellos. Se ha barajado la posibilidad de que surjan intereses contrapuestos entre grupos de empresarios norteño-fronterizos, es decir, entre el grupo maquilador y el asociado al comercio y los servicios (Salas Porras, 1987, pp. 51-58), lo que podría obstaculizar la capacidad de gestion estratégica del empresariado de la zona en su conjunto. Por el momento no parece haber un conflicto que haya tenido consecuencias más allá del ámbito de decisión estratégica de algunos grupos de la zona (como el Grupo Chihuahua). Lo más probable es que el dinamismo cada vez mayor de la industrialización maquiladora y exportadora, derivado de la diversificación de las inversiones a largo plazo de los grupos econónicos zonales, esté permitiendo que tanto las maquiladoras como los sectores de comercio y servicios apunten a incorporarse de manera ventajosa en el nuevo modelo de crecimiento economico nacional.

Lo que sí parece cada vez más lejana es la posibilidad de generar eslabonamientos productivos locales con la IME y las plantas exportadoras. Esta expectativa reiterada del Programa de Industrialización Fronteriza y de la histórica serie de decretos promulgados para la promoción de la IME sigue siendo el reto más importante para potenciar las posibilidades de desarrollo industrial de la zona. Una vez más, la clave para entender la falta de empresarios industriales asociados a la IME se encuentra en las características y exigencias de los procesos productivos de las maquiladoras, así como en la cultura empresarial local que se desarrolló en el pasado en las zonas fronterizas.

\section{La regulación microeconómica: mutaciones organizacionales e impacto laboral ${ }^{10}$}

La regulación microeconómica en el eje norteño-fronterizo se da a nivel de la firma. En la medida en que el dinamismo industrial está organizado alrededor de los intercambios entre firmas y dentro de ellas, y que el control de las cadenas mercantiles recae en las empresas transnacionales que gestionan el proceso, la industrialización en este territotio surge de la interacción de la lógica global de las empresas, por un lado, y de las configuraciones específicas de los mercados locales de trabajo, por otro.

10 Véase un análisis más detenido del tema en Alonso, Carrillo y Contreras, 1994. 
En términos generales, las empresas establecidas en el eje norteño-fronterizo han sufrido una serie de cambios relacionados sobre todo con la tecnología, las formas de producción y organización, la gestión de la mano de obra y las cadenas productivas, como veremos en los apartados siguientes.

\section{a) La transición de la muquiladora: del ensamblaje a la manufactura competitiva}

En el debate sobre el surgimiento y evolución de la JME en México, dos paradigmas intentan dar cuenta de este proceso: el neotaylorista y el de producción flexible.

El enfoque neotaylorista destaca el carácter regresivo del desarrollo de la IME, por la persistencia de condiciones y entornos de trabajo alarmantes, el deterioro ambiental, y la falta de eslabonamientos productivos nacionales derivada del ensamblaje simple que realizan las empresas. Este enfoque se basa en concepciones elaboradas en los años sesenta y setenta que vinculaban el proceso de internacionalización de la producción y el consiguiente desarrollo de empresas exportadoras a actividades intensivas en trabajo manual rutinario, de baja tecnología, desvinculadas de las economfas nacionales, con bajos salarios relativos y con alta utilización de mujeres cuyas competencias estaban circunscritas a la esfera doméstica; en suma, ve en las maquiladoras un modelo de integración vertical con regreso a las formas primitivas del taylorismo. Según la escuela de la regulación, la extensión del fordismo a países periféricos es un intento de industrialización con tecnología y modelos de consumo fordistas, pero sin sus condiciones sociales, procesos de trabajo y normas de consumo masivo. En este sentido el trasplante de ese enfoque - denominado inicialmente postaylorismo- es considerado en el mejor de los casos como una caricatura (Lipietz, 1995). Este modelo se caracteriza por hacer uso intensivo de mano de obra barata, tener actividades parceladas, ser flexible en su regulación laboral por carecer de sindicatos, utilizar poca tecnología, y estar supeditado a Estados autoritarios y represivos.

El segundo enfoque, basado en la producción flexible, ha puesto de relieve la introducción de nuevas técnicas y procesos de producción y de nuevas competencias laborales. Privilegia como objeto de investigación los sectores más modernos de la iME. A partir de varias investigaciones empíricas, ha hecho hincapié en el cstudio de los nuevos métodos de organización productiva (como el de la producción justo a tiempo y el de control total de calidad), la introduc- ción de tecnologías flexibles (máquinas de control numérico) y la aplicación de métodos de organización y control de las capacidades de trabajo y de la administración (círculos de calidad, polivalencia, sistemas de retribución, técnicas de participación, etc.). ${ }^{11}$ En general, este enfoque ha tratado de dar cuenta de una "transición" de la industria, mostrando diversos aspectos de su transformación y complejidad. Diversos estudios ${ }^{12}$ han documentado ampliamente la mutación industrial del sector de las maquiladoras, lo que les ha valido a éstas el término que aquí preferimos utilizar de maquiladoras de segunda generación.

Actualmente, está claro que a nivel de la gobernación microeconomica ha habido una difusión importante pero parcial de maquiladoras de segunda generación. Carrillo y Ramírez (1993) utilizan un análisis multivariado y encuentran que el $18 \%$ de 358 plantas maquiladoras (en tres sectores económicos) es de alta tecnología y flexibilidad, contra el $5 \%$ de los establecimientos en cl contexto nacional. Asimismo, según los gerentes consultados, el $40 \%$ de los trabajadores de producción laboraban con técnicas de organización flexibles. Por otro lado, en una encuesta no probabilística que abarcó 71 plantas maquiladoras de cuatro localidades, Wilson (1992, p. 63) encontró también un $18 \%$ de establecimientos de producción flexible. Finalmente Pelayo Martínez (1992, p. 9), en una encuesta a 18 maquiladoras de autopartes en Ciudad Juárez, verificó que $38 \%$ de ellas utilizaba el método de producción justo a tiempo, $44 \%$ los círculos de calidad y $100 \%$ el control estadístico del proceso. Si además consideramos las empresas exportadoras de automoviles y motores, vemos que la difusión de los métodos de justo a tiempo y de control total de calidad, así como de los procesos de automatización, es aún mucho mayor (véase, entre otros, Micheli, 1994; Shaiken, 1990; Carrillo, ed., 1990).

Si se analizan las estrategias que aplican firmas como Ford y General Motors (Carrillo, 1995; Micheli, 1994) y sus proveedores (Ramírez, 1995), en ambos ejes de industrialización se comprueba que la difusión y adaptación de la producción flexible es mucho mayor en las empresas exportadoras norteño-fronterizas que en las del eje centro. Este hecho marca una dife-

\footnotetext{
11 Véase más detalles acerca de las caracteristicas del modelo de producción flexible en Humphrey, ed., 1993, pp. 6 a 8; en Kaplinsky, 1993, pp. 3 a 8, y en Coriat, 1993, pp. 22 a 23.

${ }^{12}$ Como los de Echeverri-Carrol (1994), Wilson (1992), Koido (1991 y 1992), Sklair (1993), Carrillo, coord, (1993), Shaiken (1990), Brown y Domínguez (1989) y Mertens y Palomares (1988).
} 
rencia sustantiva con las estrategias de reestructuración de las plantas orientadas al mercado interno. Por tanto, todo indica que en el eje norteño-fronterizo ha habido una mayor adaptación de los principios y prácticas asociados a la producción justo a tiempo y al control total de calidad que en las empresas del eje centro.

\section{b) Relaciones laborales}

Diversos estudios reiteran que la percepción del ambiente laboral que tienen los inversionistas extranjeros es un factor importante en las decisiones de localización industrial en la zona norteño-fronteriza de México. Por ambiente laboral favorable a las empresas se ha cntendido la ausencia de sindicatos militantes, la baja tasa de conflictos laborales y la existencia de contratos colectivos flexibles en cuanto a la regulación del trabajo. Salvo unos pocos movimientos laborales y conflictos intersindicales, las relaciones lar borales en la IME, así como en las empresas exportadoras automotrices, han sido no conflictivas y contrastan en este sentido con las de empresas surgidas y desarrolladas bajo la política de industrialización por sustitución de importaciones.

En general, es posible identificar cuatro características principales de las relaciones laborales en la IME: ${ }^{13}$ i) baja conflictividad, a pesar de las reiteradas críticas sobre las condiciones de trabajo; ii) ambiente industrial altamente sindicalizado, particularmente en la frontera noreste (tasas de sindicalización de establecimientos de más del $90 \%$ ); iii) participación de sindicatos "activos" (tradicionales) y "tantasmas" (regresivo-funcionales), unos y otros incorporados a las principales confederaciones sindicales nacionales, y iv) contratos colectivos de protección altamente flexibles.

Es difficil establecer en que medida esto ha influido sobre las condiciones y el ambiente de trabajo en la IME. Lo cierto es que mientras en ella hay una evolución Iaboral y una cierta estabilidad en los sindicatos (Carrillo, coord., 1993; Carrillo y Ramírez, 1990), en las empresas orientadas al mercado interno y ubicadas en los centros industriales tradicionales se observa una involución de las condiciones laborales y un deterioro de la capacidad de negociación de los sindicatos (De la Garza, 1993).

De cualquier forma, el modo de operación de los sindicatos es un elemento importante en los mecanis-

\footnotetext{
${ }^{13}$ Sobre la base de los estudios de Covarrubias (1992), Williams y Passé-Smith (1992), y Carrillo y Ramírez (1990).
}

mos institucionales que al menos potencialmente debieran incidir en el mejoramiento de las condiciones de trabajo. Sin embargo, al parecer es más bien la escasez real de oferta de mano de obra en el eje norteño-fronterizo, y no los sindicatos, el factor que parece estar influyendo allí en el mejoramiento relativo de esas condiciones.

\section{c) Las condiciones de trabajo: salario y prestacio- nes}

Tanto en las maquiladoras norteño-fronterizas, particularmente las de segunda generación, como en las empresas exportadoras (de automóviles, motores, cemento o productos mineros), las condiciones laborales han evolucionado positivamente (por lo menos hasta antes de la crisis de 1994); en el eje centro, por el contrario, se han deteriorado (por ejemplo, al comparar la planta Ford de Hermosillo con la de Cuautitlán, o maquiladoras fronterizas con maquiladoras del centro), Esta tendencia se explica por los niveles alcanzados a principios de los años ochenta. Mientras que en el eje norteño-fronterizo la mayoría de las empresas tienen poca antigüedad y parten de un bajo nivel laboral para comenzar a ascender, las empresas del eje centro alcanzaron ventajas económicas y laborales importantes en los años sesenta y setenta, gracias a la participación de los sindicatos, pero a partir de los ochenta iniciaron su deterioro. Estas empresas han sufrido profundas reestructuraciones, traducidas en disminución del empleo, avance de la flexibilidad laboral, reducción de salarios y pérdida de espacios de negociación sindical.

Mirada la IME desde el ángulo de la producción flexible, lo que se examina es si la evolución laboral en ella es una tendencia de transformación gradual o si los cambios son poco significativos y reversibles. $\mathrm{La}$ información de que disponemos indica lo siguiente: i) desde 1982 hasta 1994 los salarios nominales y reales en las maquiladoras se incrementaron; ii) las prestaciones económicas también aumentaron, constituyendo una parte cada vez más importante del salario global (23\% en 1982, 30\% en 1990 y un pronóstico de $43 \%$ para 1997), y iii) a pesar de que muchas de las plantas maquiladoras continúan haciendo uso intensivo de mano de obra no calificada, en parte importante de ellas las habilidades aprendidas y el involucramiento en el empleo han enriquecido el trabajo.

Las condiciones laborales en la IME presentan una tendencia más positiva que en otros sectores manufactureros. Por una parte, en el contexto local los ingresos de los trabajadores de la IME son superiores a los 
devengados en otras plantas manufactureras, y sin duda se hallan sobre los mínimos generales y profesionales del país; por otra parte, la evolución de las remuneraciones muestra que aun cuando en 1980 los salarios medios en el sector manufacturero, a nivel nacional, eran 56\% supetiores que en la IME, en 1990 esa ventaja se habría reducido al $30 \%$, y las proyecciones para 1997 auguran que los de la 1ME serán 12\% más altos ese año.

En una perspectiva internacional, la IME también ha resultado ser una industria que respeta los derechos internacionales de los trabajadores y que incluso ha obtenido una mejor evaluación que zonas de producción para la exportación en otros países (Estados Unidos, Departamento del Trabajo).

Vemos asi que si bien en el eje centro las empresas devengan mayores ingresos que en la IME, con el tiempo las diferencias se han ido reduciendo apreciablemente, e incluso que las empresas exportadoras están siendo tomadas como modelo de condiciones laborales para el resto del país.

\section{d) El empleo, la calificación y la estabilidad}

En términos generales, el empleo y la estabilidad en él, así como las calificaciones laborales, han tenido evoluciones diferentes en las empresas del eje norteño-fronterizo y en las del eje centro.

En primer lugar, el empleo crece más rápidamente en las empresas exportadoras que en aquéllas orientadas al mercado doméstico; en 1994-1995 crecio $13.3 \%$ en la IME mientras que en el resto de la manufactura nacional aumentó sólo $1.5 \%$. En el eje norteño-fronterizo el promedio de trabajadores por establecimiento se ha elevado apreciablemente (por ejemplo, de 377 a 2029 entre 1985 y 1995 en las empresas de televisores), al contrario de lo que se observa en la manufactura del eje centro, y el perfil sociodemográfico de los trabajadores de la zona norteño-fronteriza tiene como característica principal la ocupación de mujeres jóvenes, de baja escolaridad y con experiencia laboral en el ramo, frente a una mayor presencia de trabajadores especializados varones en el eje centro.

En segundo lugar, la calificación laboral se ha elevado gradualmente en la IME y en las empresas exportadoras. La escolaridad media pas6 en la IME de seis a siete años y aumento el porcentaje de trabajadores con experiencia laboral previa (de $30 \%$ en 1979 a $70 \%$ en 1989). ${ }^{14}$ En el ámbito laboral, las tareas se han hecho más complejas por la difusión de algunos pro-

14 Empresas como Ford Hermosillo, por ejemplo, sólo ocupan trabajadores que hayan terminado la escuela técnica como mínimo. cesos de manufactura y el uso de nuevas tecnologías, particularmente debido a la adaptación del control total de calidad (en especial del control estadístico de los procesos y de los grupos de control de calidad). $Y$ en el ámbito organizacional, según los gerentes encuestados, el número de trabajadores calificados ha aumentado en el tiempo (del $20 \%$ en 1979 a $40 \%$ en 1989 ). Al respecto cabe aclarar que si bien el trabajo en la IME es de baja calificación en términos generales, el hecho de que la estructura ocupacional esté compuesta por un $80 \%$ de trabajadores relacionados directamente con la producción está asociado al menos con tres factores: la edad de las empresas (mientras más nueva sea menos trabajadores calificados habrá en su estructura organizativa); la alta rotación de personal (cuyo reemplazo nutre incesantemente los segmentos de baja calificación), y las estructuras organizativas compactas (por ejemplo, de cuatro categorías) dentro de las empresas.

En tercer lugar, el empleo en la ime es de hecho temporal, ya que los trabajadores abandonan constantemente los empleos. La rotación mensual media en 358 plantas analizadas en 1989 fue de $12 \%$ (contra 2\%, por ejemplo, en empresas ubicadas en Monterrey). La IME norteño fronteriza tiene las tasas de rotación más elevadas de todo el sector manufacturero mexicano; esta inestabilidad en el empleo está asociada principalmente a variables sociodemográficas (Carrillo y Santibáñez, 1993). Un amplio estudio en Tijuana encontró que las personas solteras y más jóvenes rotan más, lo cual se explica por el ciclo de vida en que se hallan y por las amplias expectativas de cmpleo en la frontera norte.

En síntesis, y simplificando la caracterización de las empresas, en el eje norteno-fronterizo y particularmente en empresas exportadoras y no maquiladoras altamente dinámicas y competitivas en el ámbito internacional, las relaciones laborales no son conflictivas, toda vez que la presencia sindical es baja, los salarios mejoran gradualmente (al menos hasta 1994) y las prestaciones aumentan su participación en el salario global. El empleo por establecimiento crece con rapidez, la calificación se eleva en forma gradual, las actividades se hacen más complejas, a la par que se introducen procesos tecnológicos más avanzados y nuevas formas de organización del trabajo, y se cuenta con una estructura flexible en el mercado de trabajo externo debido a las grandes oportunidades de empleo. Todas estas características difieren, en términos generales, de tas que se observan en empresas no exportadoras localizadas en zonas industriales tradicionales (Monterrey, Guadalajara, Puebla, etc.). 


\section{V}

\section{Algunas conclusiones}

Ha pasado más de una década desde la crisis de 1982 y muchos de los cambios estructurales inducidos por e] cambio de rumbo del modelo industrial de desarrollo nacional han tomado características precisas en su configuración territorial. Nuestro propósito en este trabajo es impulsar un enfoque alternativo a los que parten exclusivamente del análisis sectorial (como la sociología industrial) o del análisis territorial (como la ciencia regional), y plantear una hipotesis de trabajo que incluya ambos aspectos. Es claro que en este tema queda mucho por hacer, tanto a nivel conceptual como de investigación. Sin embargo, y aún en su carácter de hipotesis, hay evidencias que fundamentan la tesis de los ejes funcional-territoriales de dinamismo industrial que han caracterizado la reestructuración productiva mexicara. Esperamos que el avance de la investigación permita obtener una visión más amplia de las opciones de desarrollo regional que tienen las diferentes localidades norteño-fronterizas.

La noción de eje funcional-territorial permite reconocer tanto la heterogeneidad de la articulación productiva como el marco regulatorio que le da características de homogeneidad territorial al proceso. En términos de esta homogeneidad, cabe preguntarse en qué medida los empresarios de la zona norteño-fronteriza podrán sostener una estrategia colectiva, o si se corre el riesgo de una ruptura entre las lógicas de los diferentes sectores empresariales que operan en la zona.

En cuanto a la heterogeneidad del proceso, podemos avanzar en la identificación de la diversidad de vínculos y eslabonamientos que la IME y otras empresas exportadoras presentan con sus casas matrices y contratistas extranjeros y, en última instancia, con la diversidad estructural del sector industrial externo al que están vinculadas. Estaríamos hablando, entonces, de un escenario con diversas trayectorias de desarro$\mathrm{llo}$, con diferentes necesidades y lógicas internas de organización y control de la producción, y con distintas relaciones entre las empresas y dentro de ellas. Para analizar tales dinámicas tendríamos que contar con estudios de trayectorias de desarrollo como los que proponen Storper y Harrison (1990) para el caso de los distritos industriales. Hay muy pocos trabajos orientados en esta dirección (Mercado, 1988), aunque serían muy átiles para comprender mejor la ME. Convendría también abandonar la pretensión de seguir estudiando a la IME como una unidad de análisis homogénea. No se trata solamente de reconocer la heterogeneidad estructural de las principales variables que la definen (Carrillo, coord., 1993; González-Aréchiga y Ramírez, 1989), sino de asumir que no se trata de una industria propiamente dicha. En efecto, la IME es un conjunto de plantas manufactureras que se adscriben a un régimen arancelatio específico a fin de obtener una serie de ventajas para la exportación. Poco se ha avanzado en el análisis de la diversidad laboral desde la perspectiva de la heterogeneidad estructural de las maquiladoras. Es decir, no se ha abordado esa diversidad como producto de diferencias en sus vinculos y eslabonamientos, y paco se ha considerado la gobernación económica que la define y que encierra la respuesta a nuestros interrogantes sobre el potencial de desarrollo de este modelo.

Para plantearse ta existencia de una "cuestión regional", es necesario precisar cómo se están produciendo los cambios de la articulación regional en México; es decir, cómo se están redefiniendo las formas en que opera la organización social de la economía mexicana en las distintas regiones y localidades. Por to mismo, la premisa de este trabajo es que para precisar la naturaleza de estas tendencias estructurales en el país es necesario pasar del análisis de los procesos a nivel global al análisis de las tendencias de desarrollo de las regiones y localidades específicas. El curso de los acontecimientos en torno a la reestructuración industrial pasa por el filtro de las dinámicas regionales y locales, y en tanto no contemos con un perfil de cómo se procesan y se producen en esos tiiveles las diversas modalidades de la reestructuración, poco en realidad podemos decir acerca de su curso real. 


\section{Bibliografia}

Alonso, Jorge (1996): La especialidad social en el análisis de la reestructuración, ponencia presentada en el Seminario COLEF 3, El Colegio de la Frontera Norte (Tijuana, México, 20 a 22 de octubre de 1994)

Alonso Estrada, J., J. Carrillo y o. Contreras (1994): Mercados laborales y condiciones de trabajo en la transición de la industria maquiladora, $W$. Senderberger y 0 . Contreras (eds.), Las maquiladoras en México: presente y futuro del desarrotho industrial, Tijuana, México, Organización Internacional del Trabajo (OIT)/Ed Colegio de la Frontera Norte.

Arteaga, A., coord. (1993): Proceso de trabajo y relaciones laborales en la industriu automotriz en México. México, D.F., Universidad Autónoma Metropolitana (UAM)/Fundación Friedrich Eloert.

Brown, F. y L. Domínguez (1989): Nuevas tecnologias en la industria maquiladora de exportación, Comercio exterior, vol. 39 , $N^{\circ}$ 3, México, D.F., El Colegio de México, marzo.

Campbell, J. y L. Lindberg (1991): The state and the organization of economic activity, J. Campbell y otros (eds.), Governing the American Economy, Cambridge, Reino Unido, Cambridge University Press.

Carrillo, V. (1989): Transformaciones en la industria maquiladora de exportación, Barajas y González-Aréchiga (eds.), Las maquiladoras: ajuste estructural $y$ desarrollo regional, Tijuana, México, El Colegio de la Frontera Norte.

(1995): Flexible production in the auto sector: Industrial reorganization at Ford-Mexico, World Development, vol. 23, $\mathrm{N}^{0} \mathrm{I}$, Oxford, Reino Unido, Elsevier Science Ltd.

Carrilto, V., ed. (1990): La nueva era de to industria automotriz, Tijuana, México, El Colegio de la Frontera Norte.

Carrillo V., coord. (1993): Condiciones de empleo y capacitación en las maquiladoras de exportación en México, Tijuana, México, Secretaría del Trabajo y Prevision Social (sTPS)/El Colegio de la Frontera Norte.

Carrillo, V. y M.A. Ramirez (1990): Maquiladoras en la Frontera Norte: opinion sobre los sindicatos, Frontera Norte, vol. 2 , $\mathrm{N}^{\star} 4$, Tijuana, México, Colegio de la Frontera Norte. (1993): Nuevas tecnologias en la industria maquiladora, J. Micheli (comp.), Tectología y moderrización económica, México, D.F., UAM/Consejo Nacional de Ciencir y Tecnologa (CONACYT).

Carrillo V., y J. Santibaffez (1993): Rotación de personal en las maquiladoras de exportación en Tijuana, Tijuana, México, STPS/ El Colegio de la Frontera Norte.

Cortat, B. (1993): Pensar al revés, Madrid, Siglo XXI

Covarrubias, A. (1992): La flexibilidad en Sonora, México, D.P., Universidad Nacional Autónoma de México (UNAM), El Colegio de Sonora/Fundación Ebert.

De la Garza, E. (1993): Reestructuración productiva y respuesta sindical en México, México, D.F., UNAM, Instituto de Investigaciones Económicas/UAM.

De Oliveira, O. y B. Garcia (1993): Cambiess socioeconómicns y dinámica de los mercados de trabajo en Méxice: 1950-1992, México, D.F., El Colegio de México.

Echeverri-Carroll, E. (1994): Flexible linkages and offshore assembly facilities in developing countries, Austin, Texas, University of Texas, School of Business, mimeo.

González-Aréchiga, B. (1988): Deterioro de los términos de intercambio de la industria maquilladora: 1980-1985, Foro internacional, vol. 28, $N^{\circ} 3$, México, D.F., El Colegio de México, A.C., enero-marzo.

González-Aréchiga, B. y J.C. Ramírez (1989): Productividad sin distribución: cambio tecnológico en la maquiladora mexicnna (1980-1986), Frontera Norte, vol. 1, N 1, Tijuana, México, El Colegio de la Frontera Norte, enero-junio.
Humphrey $\mathrm{J}_{\text {., }}$ ed. (1993): Quality and productivity in industry: New strategies in developing countries, IDS Bulletin, vol. $24, \mathrm{~N}^{\circ} 2$, Brighton, Reino Unido, University of Sussex, Institute for Development Studies, abril.

INEGI (Instituto Nacional de Estadística, Geografía e Informática) (1983): Censos Económicos de 1980, México, D.F

(1995): Censos Económicos del993, México, D.F.

Kaplinsky, Raphie (1993): Implementing JIT in LDCs: from theory to practice, trabajo presentado al Workshop on Intra-firm Reorganization in the Third World Manufacturing (Brighton, 14-16 de abril), University of Sussex. Institute for Development Studies.

Koido, A. (1991); The color television industry: Japanese-U.S. competition and Mexico's maquiladoras, en Manufacturing across borders and oceans, Monograph Series, No.36, Sau Diego, California, Center for US-Mexican Studies/ University of Califomia.

(1992): U.S.-Iapanese competition and auto component maquiladoras: The case of wiring hamess sector in the State of Chihuahua. Trabajo presentado a la XVII Conferencia Internacional de la Latin American Studies Association, Los Angeles, California, Center for US-Mexican Studies/University of Califomia.

Lipietz, A. (1995): De Toyota-City a la Ford-Hermosillo: la japonización de pacotilla, El Cotidiano, $\mathrm{N}^{\circ} 67$, México, D.F., UAM, enero-febrero.

Mercado, A. (1988): Difusion de tecnología basada en lo microelectrónica en la industria metalmecúnica mexicana, México, D. F., El Colegio de México, noviembre.

Mertens, L. y L. Palomares (I988): El surgimiento de un nuevo tipo de trabajador en la industria de alta tecnologfa. El caso de la electrónica, E. Gutiérez (comp.), Restructuración productiva y clase obrera, México, D.F., Siglo XXI/UNAM.

Micheli, J. (1994): Nueva manufactura. Globalización y producción de astomíviles en Méxict, México, D.F., UNAM, Facultad de Economía.

Mortimore, M. (1995): Transforming sitting ducks into flying geese: the Mexican automobile industry. Desartollo Productiyo. $N^{*}$ 26, LC/G.1865, Santiago de Chile, Comision Económica para América Latina y el Caribe (CEPAL).

Pelayo Martínez, A. (1992): Nuevas tecnologías en la industrịa maquiladora de autopartes en Ciudad Juárez. Materiales y obseryaciones de campo, Cuadernor de trabajo, $\mathrm{N}^{\circ} 6$, Ciudad Juárez, Universidad Autónoma de Ciudad Juárez, Unidad de Estudios Regionales, otono.

Ramírez, J.C. (1995): La organización justo a tiempo en la industria automotriz del norte de México. Nuevos patrones de localización y eficiencia, Documentos de trabajo, $\mathrm{N}^{\circ} 33, \mathrm{Méxi}-$ co, D.F., Centro de Investigación y Docencia Econóniças.

Salas Porras, Alejandro (1987): Maquiladoras y burguesia regional, El Cotidiano, Núsmero especial 1, Ciudad de México, UAM.

Sklair, L. (1993): Assembling for Development. The Maquila Industry in Mexico and the United States, San Diego, California, Center for U.S.-Mexican Studies/University of California.

Shaiken, H. (1990): Mexico in the global economy, Monograph Series, $N^{\circ} 33$, San Diego, California, Center for U.S.-Mexican Studies/University of California.

Storper, M. y B. Harrison (1990): Flexibility, Hierarchy and Regional Development: The Changing Structure of Industital Production Systems and Their Forms of Governonce in the 1990s, Working Paper, N 9002, Los Angeles, California, Graduate School of Architecture and Urban Planning/Universily of California at Los Angeles (UCLA). 
Willjarns, E.J. y J.T Passe-Smith (1992): The Unionization of the Maquiladora Industry: The Tamaulipas Case in National Context, San Diego, California, San Diego State University, Institute for Regional Studies of the Californias.
Wilson, P.A. (1992): Exports and Local Development. Mexico's New Maquiladoras, Austin, Texas, University of Texas Press. 